\title{
Detection and recognition of intensity changes in tone and noise: The detection-recognition disparity*
}

\author{
NEIL A. MACMILLAN \\ Brooklyn College of the City Lniversity of New York, Brooklyn, New York 11210
}

\begin{abstract}
Recognition of increments vs decrements in auditory intensity improves with signal duration, relative to detection of increments and decrements. This effect obtains whether the background stimulus is a tone, noise, or a tone with noise masker, and is largely uninfluenced by the rise time of the signals. These data are inconsistent with detection models in which the $\mathrm{O}$ makes only one sensory observation during each observation interval, but can be described in terms of a neural timing model in which transients play a critical role.
\end{abstract}

The problems of detection (distinguishing a signal from the absence of a signal) and recognition (distinguishing signals from each other) are frequently investigated in similar paradigms and explained by similar theories (Luce, 1963; Tanner, 1956). Yet basic facts concerning the relation between the two are not well established. For example, it is not clear whether signals must always be recognized in order to be detected. Shipley (1965) argues from the results of her simultaneous detection and recognition experiment that this is true, but Lindner's (1968) data from a similar experiment do not support such a hypothesis.

Macmillan (1971) presented evidence of a different sort that the detection of signals was not completely dependent on their recognition. At short durations (less than about $100 \mathrm{msec}$ ), Os' ability to recognize whether a small increment or decrement in a pure tone background had been presented was comparable to their ability to detect those signals. At longer durations, their recognition performance exceeded their detection performance by approximately the amount predicted by a signal detection theory model in which the sensory effects due to the three signals (decrement, no change, and increment) are assumed to lie upon a single decision axis. This effect of duration on recognition, relative to detection, will be referred to as the "detection-recognition disparity."

The interpretation of these data suggested by Macmillan was as follows: In addition to an integrative detector (ID), which accumulates information about the stimulus over time and offers an identification of the signal, the $\mathrm{O}$ also has a change detector (CD), which

*Support for this investigation was provided by the City University of New York Faculty Research Award Program (Experiments I-III) and the Society of Sigma Xi (Experiments IV and V). I am grateful to David $H$. Raab for the use of his laboratory, and to Norma Graham for her many helpful comments on an earlier draft of this manuscript. Requests for reprints should be sent to Neil A. Macmillan, Department of Psychology, Brooklyn College of the City Lniversity of New York, Brooklyn, N.Y. 11210. operates on signal onsets (and perhaps offsets). and thus does not integrate over time, and which only conveys information about the presence or absence of a signal. not about its identity. Both mechanisms combine in an unspecified manner to yield detection performance. but in recognition experiments only the ID is useful. In detection experiments, the $C D$ will be relatively more important at short durations. where the ID is less reliable, so recognition performance will increase relative to detection as duration increases. i.e. the detection-recognition disparity will obtain. A model of this sort differs from most existing models of detection in proposing that detection (1) is in part nonintegrative. (2) is in part nonidentifying, and (3) involves more than one process.

The positing of more than one process is perhaps the most serious departure from tradition. One-process models have worked fairly well in auditory detection and should not be abandoned for an apparently more complex view unless the latter is clearly necessary. Leshowitz and Wightman (1972) have offered an explanation of Macmillan's (1971) data in terms of a one-process model, their (1971) variable filter model for tone-on-tone masking. They point out that the power spectra of the signals used in the experiment include nonnegligible amounts of energy (about $10 \%$ of the total) more than $1 /$ (signal duration) $\mathrm{Hz}$ from the signal frequency. Evidence from Leshowitz and Wightman (1971) suggests that Os can make use of this "energy: splatter" to improve the detectability of short tones, presumably by moving an internal filter. of the sort customarily assumed by detection theorists (e.g., Green $\&$ Swets, 1966), off the signal frequency to a part of the spectrum where the signal-to-noise ratio is better. Since short tones have wider spectra than long ones, this adjustment will be most profitable at the shortest durations, improving detection at those durations. Recognition of increments and decrements. however. requires that the internal filter be moved to the signal frequency, where all the information relevant to a decision between increments and decrements is contained. 
This account is largely consistent with Macmillan's (1971) data [see Macmillan (1972) for exceptions] and apparently salvages one-process detection theories at the expense only of assuming considerable observer control over the presumed internal filter. However. the explana. tion rests heavily on the characteristics of the stimulus situation in Macmillan's experiment. The present paper reports the effects of altering the stimulus situation by using (in separate experiments): tonal signals with nonzero rise times (Experiments I and II). noise signals (Experiment III), and tonal signals in the presence of noise (Experiments IV and V). In these experiments, Leshowitz and Wightman's (1971) model predicts an elimination (or at least a weakening) of the detection-recognition disparity. To anticipate, although the results of these experiments are not inconsistent with the off-frequency listening hypothesis, they clearly indicate that this hypothesis cannot be the sole explanation of the detection-recognition disparity, since this effect appears in a number of conditions in which off-frequency listening is unprofitable. Thus, the data argue against the off-frequency listening hypothesis as an explanation of the detection-recognition disparity and strongly support the existence of a detection mechanism which does not identify signals and whose performance is independent of duration.

\section{EXPERIMENT I: EFFECTS OF SIGNAL RISE TIME}

If the detection-recognition disparity is due to off-frequency listening, then alterations in the spectra of the signals should alter the effect. One fairly simple method for altering the spectrum of a tonal signal, traditionally used by Es wishing to reduce energy splatter, is to gate the signal on with a nonzero rise time. This can be accomplished in either of two ways: by bandpass filtering the signal or by using an electronic switch to gate the signal on and off with a trapezoidal envelope. These two procedures do not have exactly equivalent effects on the signal spectrum, but they both serve to reduce the proportion of the energy that is off-frequency. Some examples of the spectra of both types of signals are given in Wightman (1971).

In this experiment, an electronic switch was used to vary rise time. Consider a $1,000-\mathrm{Hz}$ tone that is gated on and off with a trapezoidal envelope and lasts $50 \mathrm{msec}$. To get a feel for the amount of energy splatter in such a signal, we compute the power spectrum and estimate the proportion of the energy falling within one critical bandwidth centered at the signal frequency. ${ }^{1}$ For a $1,000-\mathrm{Hz}$ signal, the critical band is approximately $160 \mathrm{~Hz}$ (Scharf, 1970, p. 162). For 0.5-msec rise times, the proportion of energy not in the band between 920 and $1,080 \mathrm{~Hz}$ is .023 ; for $5 \mathrm{msec}$ rise times, this proportion is only .005. This gives an overall decrease in off-frequency energy of about $6.6 \mathrm{~dB}$ : thus, if the splatter is just detectable when the rise time $150.5 \mathrm{msec}$. it will not be detectable when the rise time is $5.0 \mathrm{msec}^{2}$ A similar effect occurs with longer signals. although the proportions of off-frequency energy are lower. For a $300-m s e c$ burst. the two rise times above yield proportions of off-frequency energy of .003 and .0006 .

Thus. increasing rise time. like increasing duration. decreases the proportion of the signal energy that is off-frequency. If the $\mathrm{O}$ is using the off-frequency energy in his decision. increasing the signal rise time should result in a decline in his performance (i.e.. an increase in threshold). In addition, lengthening the rise time should reduce the detection-recognition disparity under this hypothesis: Without a significant proportion of energy off-frequency, the $\mathrm{O}$ should be forced to attend to the center frequency in both detection and recognition conditions, and his recognition performance should not improve as much with signal duration relative to detection performance.

\section{Procedures}

Two Os, one of whom was the investigator, served individually: OA.B. was paid at an hourly rate. Os sat in a double-walled IAC acoustic chamber. and stimuli were presented to them through PDR-10 earphones. At least $8 \mathrm{~h}$ of practice were given before any data were collected. and most experimental conditions were sampled in this period.

A $1,000-\mathrm{Hz}$ tone was presented continuously to the $\mathrm{O}$ 's right ear at $62 \mathrm{~dB}$ SPL. Signals were increments and decrements in the amplitude of the background tone and were turned on by an electronic switch 1 Grason-Stadler 829S61). Signal duration (25. 50.100 , and $300 \mathrm{msec}$ ) and rise time $(0.5 .1 .0$, and $5.0 \mathrm{msec})$ were varied. All signals of the same nominal duration were adjusted in duration so that their energies were equal: a signal with a nominal duration of $T \mathrm{sec}$ and rise time of $\mathrm{I}$ sec was actually $T+4 r / 3 \mathrm{sec}$ long from onset to offset.

Each two-alternative temporal forced-choice trial began with a faint warning click to the $O$ 's left ear. The first signal interval followed $1.5 \mathrm{sec}$ after the click. and the second interial was spaced so that the time between the end of a signal in the first interval and the beginning of a signal in the second interval was always $750 \mathrm{msec}$. The signal intervals were marked by faint. brief $(10$-msec) lights on the O's response panel. The $O$ responded by pushing one of two microswitches, and immediate feedback was provided on the response panel. The response initiated the next trial; this procedure produced one trial in approximately $5 \mathrm{sec}$. The two possible stimulus events on each trial were always equally likely.

Experimental sessions lasted $90 \mathrm{~min}$ and were broken into two or three parts by short breaks during which the $O$ could leave the chamber. Trials were presented in blocks of approximately 100 ; the first block of trials each day was practice and was not included in the analysis. Os served about 5 days per week.

A single experimental session consisted of increment detection, decrement detection. and increment-decrement recognition at the same signal duration and rise time. The two detection conditions were always presented first (sometimes increments first, sometimes decrements). An up-down procedure was used to estimate the "threshold" intensity as follows: A block of trials began with the signal level as close as possible to threshold, based on practice data. If the $O$ made five correct responses before he made two incorrect ones. the signal level was decreased; otherwise it was increased. The step size was approximately constant, as measured in terms of $\Delta v, v$, the proportional change in voltage represented br the signal. and was equal to $.01 .^{3}$ Two blocks of 100 trials each were run. and the 
Table 1

Results of Experiment I: Effects of Rise Time on Detection and Recognition of Increments and Decrements in a Pure Tone

\begin{tabular}{|c|c|c|c|c|c|c|c|c|c|}
\hline \multirow[b]{2}{*}{$\begin{array}{l}\text { Rise } \\
\text { Time } \\
(\text { Msec) }\end{array}$} & \multirow[b]{2}{*}{$\begin{array}{l}\text { Dura- } \\
\text { tion } \\
\text { (Msec) }\end{array}$} & \multicolumn{4}{|c|}{$\mathrm{OAB}$} & \multicolumn{4}{|c|}{ O NM } \\
\hline & & $\begin{array}{l}\text { Increment } \\
\text { Threshold } \\
\text { (dB) }\end{array}$ & $\begin{array}{c}\text { Decrement } \\
\text { Threshold } \\
\text { (dB) }\end{array}$ & $\begin{array}{c}\text { Percent } \\
\text { Correct } \\
\text { in } \\
\text { Recog- } \\
\text { nition }\end{array}$ & $\begin{array}{l}\text { Repli- } \\
\text { cation? }\end{array}$ & $\begin{array}{l}\text { Increment } \\
\text { Threshold } \\
\text { (dB) }\end{array}$ & $\begin{array}{c}\text { Decrement } \\
\text { Threshold } \\
\text { (dB) }\end{array}$ & $\begin{array}{c}\text { Percent } \\
\text { Correct } \\
\text { in } \\
\text { Recog- } \\
\text { nition }\end{array}$ & $\begin{array}{l}\text { Repli- } \\
\text { cation? }\end{array}$ \\
\hline 0.5 & $\begin{array}{r}25 \\
50 \\
100 \\
300\end{array}$ & $\begin{array}{r}-9.3 \\
-10.8 \\
-11.6 \\
-13.4\end{array}$ & $\begin{array}{r}-9.5 \\
-10.5 \\
-11.9 \\
-13.3\end{array}$ & $\begin{array}{r}80 \\
80 \\
81 \\
100\end{array}$ & $\begin{array}{l}x \\
x \\
x\end{array}$ & $\begin{array}{r}-7.6 \\
-9.0 \\
-9.9 \\
-10.9\end{array}$ & $\begin{array}{l}-6.5 \\
-8.6 \\
-9.3 \\
-9.4\end{array}$ & $\begin{array}{l}76 \\
73 \\
91 \\
93\end{array}$ & $\begin{array}{l}x \\
x\end{array}$ \\
\hline 1.0 & $\begin{array}{r}25 \\
50 \\
100 \\
300\end{array}$ & $\begin{array}{r}-8.7 \\
-11.4 \\
-11.2 \\
-13.8\end{array}$ & $\begin{array}{r}-7.5 \\
-9.8 \\
-10.5 \\
-10.6\end{array}$ & $\begin{array}{l}77 \\
73 \\
79 \\
94\end{array}$ & $x$ & $\begin{array}{r}-6.6 \\
-9.4 \\
-10.5 \\
-11.2\end{array}$ & $\begin{array}{r}-6.4 \\
-8.6 \\
-9.3 \\
-10.6\end{array}$ & $\begin{array}{l}81 \\
69 \\
82 \\
95\end{array}$ & $\begin{array}{l}x \\
x\end{array}$ \\
\hline 5.0 & $\begin{array}{r}25 \\
50 \\
100 \\
300\end{array}$ & $\begin{array}{r}-8.9 \\
-10.1 \\
-11.9 \\
-12.9 \\
\end{array}$ & $\begin{array}{r}-7.9 \\
-10.2 \\
-10.8 \\
-10.8 \\
\end{array}$ & $\begin{array}{l}79 \\
78 \\
70 \\
93\end{array}$ & $x$ & $\begin{array}{r}-6.7 \\
-9.1 \\
-9.2 \\
-11.7 \\
\end{array}$ & $\begin{array}{r}-6.6 \\
-7.7 \\
-8.6 \\
-10.9 \\
\end{array}$ & $\begin{array}{l}89 \\
78 \\
88 \\
91 \\
\end{array}$ & $\begin{array}{l}x \\
x\end{array}$ \\
\hline
\end{tabular}

mean of the pooled data was used to estimate the threshold. 4

In the recognition condition, each trial was either an increment followed by a decrement or a decrement followed by an increment: the intensities used were the thresholds estimated in the detection conditions. Two recognition blocks of 100 trials each were run. 5

\section{Results and Discussion}

Table 1 gives the threshold increment and decrement, measured as $10 \log (\Delta I / I)$, where $I$ is the background power and $\Delta \mathrm{I}$ the difference between background power and background-plus-signal power; the table also gives the percent correct in recognition. For most conditions, the detection-recognition disparity appears: percent correct in recognition is at about the level of detection performance at the short durations, but about $90 \%$ at the long durations: detection performance is assumed constant $(73.5 \%$ correct) at all durations. However, there are some nonmonotonicities in the recognition data, and for the $5-\mathrm{msec}$ rise time condition, N.M. does not clearly show the detection-recognition disparity. The apparent difference between the two Os could conceivably reflect the use of off-frequency listening by N.M. but not by A.B. Inter-O differences are not surprising when performance depends on the O's listening strategy.

At short durations ( 25 and $50 \mathrm{msec}$ ), the thresholds for the fast rise-time conditions tend to be lower than for the slower rise-time conditions: The slopes of the threshold vs log rise time functions for these two durations differ significantly from zero $(p<.05$, two-tailed $t$ test). For longer signals, there seems to be little difference. This is consistent with the data of Garner (1947) and Creelman (1964). both of whom found that short tones were slightly less detectable when they were bandpass filtered fand thus had nonzero rise times).

\section{EXPERIMENT II: . EFFECTS OF SIGNAL RISE TIME AND FREQUENCY}

The second experiment was similar to the first. Rise time was either 1 or $10 \mathrm{msec}$. The effects of this variation on the percentage of signal energy outside the critical band are similar to the effects of the variation from 0.5 to $5.0 \mathrm{msec}$ in Experiment I. For a $250-\mathrm{Hz}$ signal with a duration of $50 \mathrm{msec}$ and a rise time of $1 \mathrm{msec}$, the proportion of the energy outside the critical band (200-300 Hz; see Scharf, 1970) is .034: for an otherwise identical signal with a $10-\mathrm{msec}$ rise time, this proportion is .003 .

Signal frequency was also varied in Experiment II. Although the width of the spectrum of a short tone does not vary much with frequency, the width of the O's critical band varies considerably. Thus, at $4,000 \mathrm{~Hz}$, Scharf (1970) estimates the critical band to extend from 3,700 to $4,400 \mathrm{~Hz}$. At this frequency, changing the rise time of a $50-\mathrm{msec}$ burst from 1 to $10 \mathrm{msec}$ changes the proportion of energy outside the critical band from .0014 to .00001 . Thus. the amount of off-frequency energy, estimated in this manner. is very slight. The effect of rise time on this splatter is substantial. but it is not obvious that the $O$ will be sensitive to such small amounts of energy.

\section{Procedures}

This experiment differed from the first experiment in the following wavs: (1) The frequencies used were 250 and $4.000 \mathrm{~Hz}$. (2) The rise times used were 1 and $10 \mathrm{msec}$. (3) The durations used were 50.100 . and $300 \mathrm{msec}$. In cases where recognition performance had not reached a high level at 300 msec. $500-m s e c$ conditions were run for both rise times. (4) Both Os were naive. 
Table 2

Results of Experiment Il: Effects of Rise Time and Frequency on Detection and Recognition of Increments and Decrements in a Pure Tone

\begin{tabular}{|c|c|c|c|c|c|c|c|c|c|c|}
\hline \multirow[b]{2}{*}{$\begin{array}{c}\text { Frequenc! } \\
\text { (Hz) }\end{array}$} & \multirow[b]{2}{*}{$\begin{array}{c}\text { Rise } \\
\text { Time } \\
\text { (Msec) }\end{array}$} & \multirow[b]{2}{*}{$\begin{array}{l}\text { Dura- } \\
\text { tion } \\
\text { (.Msec) }\end{array}$} & \multicolumn{4}{|c|}{ O C.I } & \multicolumn{4}{|c|}{$\mathrm{O} \| \mathrm{L}$} \\
\hline & & & $\begin{array}{l}\text { Increment } \\
\text { Threshold } \\
(\mathrm{dB})\end{array}$ & $\begin{array}{l}\text { Decrement } \\
\text { Threshold } \\
\text { (dB) }\end{array}$ & $\begin{array}{l}\text { Percent } \\
\text { Correct } \\
\text { in } \\
\text { Recog- } \\
\text { nition }\end{array}$ & $\begin{array}{l}\text { Repli- } \\
\text { cation? }\end{array}$ & $\begin{array}{l}\text { Increment } \\
\text { Threshold } \\
\text { (dB) }\end{array}$ & $\begin{array}{c}\text { Decrement } \\
\text { Threshold } \\
\text { (dB) }\end{array}$ & $\begin{array}{l}\text { Perient } \\
\text { Correst } \\
\text { in } \\
\text { Recog- } \\
\text { nition }\end{array}$ & $\begin{array}{l}\text { Repli- } \\
\text { "ation? }\end{array}$ \\
\hline+000 & 1.0 & $\begin{array}{r}50 \\
100 \\
300 \\
500\end{array}$ & $\begin{array}{l}-10.2 \\
-10.3 \\
-14.2 \\
-12.2\end{array}$ & $\begin{array}{r}-10.7 \\
-9.9 \\
-13.3 \\
-12.0\end{array}$ & $\begin{array}{l}76 \\
70 \\
76 \\
98\end{array}$ & $x$ & $\begin{array}{l}-10.4 \\
-10.7 \\
-13.6\end{array}$ & $\begin{array}{l}-9.5 \\
-10.7 \\
-11.4\end{array}$ & $\begin{array}{l}58 \\
61 \\
89\end{array}$ & \\
\hline & 10.0 & $\begin{array}{r}50 \\
100 \\
300 \\
500\end{array}$ & $\begin{array}{r}-9.3 \\
-9.8 \\
-12.5 \\
-11.9\end{array}$ & $\begin{array}{l}-10.1 \\
-10.2 \\
-11.5 \\
-11.3\end{array}$ & $\begin{array}{l}72 \\
74 \\
96 \\
84\end{array}$ & $x$ & $\begin{array}{r}-9.2 \\
-11.5 \\
-14.4\end{array}$ & $\begin{array}{r}-7.8 \\
-9.9 \\
-11.9\end{array}$ & $\begin{array}{l}63 \\
55 \\
79\end{array}$ & \\
\hline 250 & 1.0 & $\begin{array}{r}50 \\
100 \\
300\end{array}$ & $\begin{array}{l}-6.8 \\
-7.5 \\
-8.7\end{array}$ & $\begin{array}{l}-7.1 \\
-7.3 \\
-9.0\end{array}$ & $\begin{array}{l}75 \\
80 \\
91\end{array}$ & $\begin{array}{l}x \\
x\end{array}$ & $\begin{array}{l}-9.2 \\
-9.9 \\
-8.5\end{array}$ & $\begin{array}{l}-8.9 \\
-9.9 \\
-9.1\end{array}$ & $\begin{array}{l}62 \\
67 \\
94\end{array}$ & $\mathrm{~s}$ \\
\hline & 10.0 & $\begin{array}{r}50 \\
100 \\
300\end{array}$ & $\begin{array}{l}-6.3 \\
-6.9 \\
-9.6\end{array}$ & $\begin{array}{l}-7.1 \\
-7.9 \\
-8.9\end{array}$ & $\begin{array}{l}66 \\
70 \\
90\end{array}$ & & $\begin{array}{r}-8.5 \\
-10.0 \\
-10.6\end{array}$ & $\begin{array}{l}-8.8 \\
-9.5 \\
-9.3\end{array}$ & $\begin{array}{r}68 \\
74 \\
100\end{array}$ & $x$ \\
\hline
\end{tabular}

\section{Results and Discussion}

Table 2 gives the results of the experiment. The detection-recognition disparity (recognition improving with duration as detection performance remains constant) occurs in all conditions. although C.M.'s $4,000-\mathrm{Hz} 10-\mathrm{msec}$ rise time data are noisy. There is no obvious effect of frequency. As in Experiment $I$, there is a tendency for the $50-\mathrm{msec}$ signals to yield lower thresholds when the rise time is short $(p<.01$. two-tailed test).

Although there are hints in the data of these experiments that off-frequency listening may be taking place (e.g., the absence of the detection-recognition disparity for ON.M. at the longest rise time in Experiment I, and the effects of rise time on threshold at short durations), it seems fair to conclude that off-frequency listening does not entirely account for the detection-recognition disparity in these experiments, since the extent of the effect is not generally related to the proportion of signal energy lying outside the critical band (or to any similar measure). The situation is not, however, clear-cut. The spectra of the signals in different conditions differ considerably; if an $\mathrm{O}$ is able to adjust an internal filter in response to these differences, his performance will depend heavily on how he makes this adjustment-there is no reason why he must behave optimally or always according to tine same rule. A convincing demonstration that the detection-recognition disparity does not depend on off-frequency listening requires a situation in which the conditions allowing off-frequency listening are minimized. Such a situation is investigated in the next experiment.

\section{EXPERIMENT III: INCREMENTS AND DECREMENTS IN A NOISE BACKGROUND}

The optimal stimulus condition for testing the off-frequency listening explanation would have an identical signal-to-noise ratio at all points of the spectrum. This situation is approximated if the signals to be detected and recognized are increments and decrements in wideband noise. The spectra of the signals and of the masker will then be quite similar, and the location of the $O$ 's internal filter can have little effect on his performance, no matter what strategies he adopts.

\section{Procedures}

The procedures and Os used were the same as in Experiment Il, with the following exceptions: Signals were increments and decrements in a continuous noise background with a total SPL of $62 \mathrm{~dB}$, produced by a General Radio 1390-B noise generator and put through a Krohn-Hite $330 \mathrm{M}$ bandpass filter whose 3-dB cutoff points were 194 and $5,194 \mathrm{~Hz}$. The filter had a nominal attenuation of $24 \mathrm{~dB} /$ octave. In the threshold estimation conditions, the intensity difference between adjacent levels was $3 \mathrm{~dB}$.

\section{Results and Discussion}

The results are given in Table 3 . There is no evidence for (and scant possibility of) off-frequency listening in these data, yet the detection-recognition disparity seems just as robust as with tones. For both Os and both rise times, recognition performance improves with duration in the usual way. detection performance being held constant. 
Table 3

Results of Experiment III: Detection and Recognition of Increments and Decrements in Broad-Band Noise

\begin{tabular}{|c|c|c|c|c|c|c|c|c|c|}
\hline \multirow[b]{2}{*}{$\begin{array}{l}\text { Rive } \\
\text { Time } \\
\text { (Msec) }\end{array}$} & \multirow[b]{2}{*}{$\begin{array}{l}\text { Durit- } \\
\text { tion } \\
\text { (1)ised }\end{array}$} & \multicolumn{4}{|c|}{ OCII } & \multicolumn{4}{|c|}{$O W L$} \\
\hline & & $\begin{array}{l}\text { Increment } \\
\text { Threshold } \\
\text { (dB) }\end{array}$ & $\begin{array}{l}\text { Decrement } \\
\text { Threshold } \\
\text { (dB) }\end{array}$ & $\begin{array}{l}\text { Percent } \\
\text { Correct } \\
\text { in } \\
\text { Recog- } \\
\text { nition }\end{array}$ & $\begin{array}{l}\text { Repli- } \\
\text { cation? }\end{array}$ & $\begin{array}{l}\text { Increment } \\
\text { Threshold } \\
\text { (dB) }\end{array}$ & $\begin{array}{l}\text { Decrement } \\
\text { Threshold } \\
\text { (dB) }\end{array}$ & $\begin{array}{l}\text { Percent } \\
\text { Correct } \\
\text { in } \\
\text { Recog- } \\
\text { nition }\end{array}$ & $\begin{array}{l}\text { Repli- } \\
\text { cation? }\end{array}$ \\
\hline 1.0 & $\begin{array}{r}50 \\
100 \\
500 \\
500\end{array}$ & $\begin{array}{r}7.0 \\
10.0 \\
9.8\end{array}$ & $\begin{array}{l}-6.6 \\
-8.1 \\
-8.6\end{array}$ & $\begin{array}{l}62 \\
65 \\
86\end{array}$ & $x$ & $\begin{array}{r}-7.5 \\
-8.0 \\
-10.7 \\
-10.3\end{array}$ & $\begin{array}{r}-7.2 \\
-7.7 \\
-11.4 \\
-10.4\end{array}$ & $\begin{array}{l}64 \\
77 \\
69 \\
92\end{array}$ & \\
\hline 10.0 & $\begin{array}{r}50 \\
100 \\
300 \\
500\end{array}$ & $\begin{array}{r}8.2 \\
7.4 \\
-11.0\end{array}$ & $\begin{array}{r}-7.4 \\
-7.5 \\
-9.8\end{array}$ & $\begin{array}{l}72 \\
82 \\
90\end{array}$ & & $\begin{array}{r}-7.0 \\
-10.8 \\
-11.1 \\
-11.9\end{array}$ & $\begin{array}{r}-8.0 \\
-8.5 \\
-10.1 \\
-9.1\end{array}$ & $\begin{array}{l}68 \\
74 \\
84 \\
96\end{array}$ & \\
\hline
\end{tabular}

\section{EXPERIMENT IV: TONAL INCREMENTS AND DECREMENTS IN THE PRESENCE OF NOISE}

An aspect of these data that is, in principle, relevant to both change detection and off-frequency listening is the nature of the relation between increment (or decrement) threshold and duration. Macmillan (1971) and Leshowitz and Wightman (1972) both argue that shallow intensity-duration curves (i.e., little effect of increasing duration) must always occur in conjunction with the detection-recognition disparity. Table 4 gives the slopes. in decibels per log unit of duration, of the least-squares best-fitting lines through the threshold points for Experiments I-III. Unfortunately, strong conclusions cannot be drawn from these computations, for several reasons. There is considerable inter-O variability. Many of the curves whose "slopes" are given are noticeably nonlinear. Most seriously, it is hard to know how shallow the slopes would need to be to satisfy the prediction.

In this experiment, an attempt is made to manipulate the slope of the intensity-duration function in order to see whether the detection-recognition disparity will also be altered. The manipulation used is the addition of a "noise floor" to a tonal background and signals. Evidence that the addition of noise will increase the amount of temporal integration in this situation was found by Leshowitz and Wightman (1971). They observed a complete absence of temporal integration between 10 and $100 \mathrm{msec}$ when signals were unfiltered increments in the intensity of a pure tone; however, when a continuous noise masker was added to the tone, the threshold for the 100-msec tone was lower than it was for the $10-\mathrm{msec}$ tone.

\section{Procedures}

The experiments with noise were done at the same time and with the same Os as the study (without noise) reported as Experiment 3 in Macmillan (1971). The procedures are described in detail in that article. The main departures from the procedures described for Experiments I-III are: (1) The tone had a frequency of $1,000 \mathrm{~Hz}$ and was presented at $56 \mathrm{~dB}$ SPL. (2) Signal rise times were fast. (3) Trials were not self-paced. but were presented to the $O$ at a rate of one every $3 \mathrm{sec}$. (4) The time between the offset of a signal in the first interval and the onset of a signal in the second was approximately $400 \mathrm{msec}$. (5) Stimuli were presented binaurally through TDH-39 earphones. (6) The method for estimating the threshold intensity was less formal; thus, in this experiment. rather than all estimated threshold signals being assumed equally detectable,

Table 4

Slopes of Intensity-Duration Relations for Experiments I-IV

\begin{tabular}{|c|c|c|c|c|c|}
\hline $\begin{array}{c}\text { Experi- } \\
\text { ment }\end{array}$ & $\begin{array}{l}\text { Stimulus } \\
\text { Condition }\end{array}$ & $\mathrm{O}$ & $\begin{array}{l}\text { Rise } \\
\text { Time } \\
\text { (Msec) }\end{array}$ & $\begin{array}{l}\text { Incre- } \\
\text { ment } \\
\text { Slope } \\
\text { (dB/Log } \\
\text { Lnit) }\end{array}$ & $\begin{array}{l}\text { Decre- } \\
\text { ment } \\
\text { Slope } \\
\text { (dB/Log } \\
\text { Unit) }\end{array}$ \\
\hline \multirow[t]{2}{*}{1} & 1000-Hz Tone & $\mathrm{AB}$ & $\begin{array}{l}0.5 \\
1.0 \\
5.0\end{array}$ & $\begin{array}{l}-3.69 \\
-4.28 \\
-3.81\end{array}$ & $\begin{array}{l}-3.59 \\
-2.65 \\
-2.45\end{array}$ \\
\hline & & NM & $\begin{array}{l}0.5 \\
1.0 \\
5.0\end{array}$ & $\begin{array}{l}-2.99 \\
-4.02 \\
-4.28\end{array}$ & $\begin{array}{l}-2.49 \\
-3.67 \\
-3.95\end{array}$ \\
\hline \multirow[t]{4}{*}{ II } & $4000-\mathrm{Hz}$ Tone & $\mathrm{CH}$ & $\begin{array}{r}1.0 \\
10.0\end{array}$ & $\begin{array}{l}-5.42 \\
-4.25\end{array}$ & $\begin{array}{l}-3.69 \\
-1.88\end{array}$ \\
\hline & & WL & $\begin{array}{r}1.0 \\
10.0\end{array}$ & $\begin{array}{l}-4.29 \\
--6.63\end{array}$ & $\begin{array}{l}-2.35 \\
-5.17\end{array}$ \\
\hline & $250-\mathrm{Hz}$ Tone & $\mathrm{CM}$ & $\begin{array}{r}1.0 \\
10.0\end{array}$ & $\begin{array}{l}-2.45 \\
-4.37\end{array}$ & $\begin{array}{l}-2.54 \\
-2.29\end{array}$ \\
\hline & & $W L$ & $\begin{array}{r}1.0 \\
10.0\end{array}$ & $\begin{array}{l}+1.08 \\
-2.57\end{array}$ & $\begin{array}{l}-0.08 \\
-0.54\end{array}$ \\
\hline \multirow[t]{2}{*}{ III } & Noise & $\mathrm{CMI}$ & $\begin{array}{r}1.0 \\
10.0\end{array}$ & $\begin{array}{l}-3.23 \\
-3.96\end{array}$ & $\begin{array}{l}-2.42 \\
-3.24\end{array}$ \\
\hline & & $W L$ & $\begin{array}{r}1.0 \\
10.0\end{array}$ & $\begin{array}{l}-4.25 \\
-4.85\end{array}$ & $\begin{array}{l}-5.61 \\
-2.76\end{array}$ \\
\hline IV & $1000-\mathrm{Hz}$ Tone & $\begin{array}{l}\text { EB } \\
\text { RZ } \\
\text { KR }\end{array}$ & $\begin{array}{l}0.0 \\
0.0 \\
0.0\end{array}$ & $\begin{array}{l}-2.61 \\
-2.41 \\
-2.82\end{array}$ & $\begin{array}{l}-2.24 \\
-1.66 \\
-1.74\end{array}$ \\
\hline & $\begin{array}{l}\text { 1000-Hz Tone } \\
\text { with Noise } \\
1 \text { loor }\end{array}$ & $\begin{array}{l}\text { EB } \\
\mathrm{RZ} \\
\mathrm{KR}\end{array}$ & $\begin{array}{l}0.0 \\
0.0 \\
0.0\end{array}$ & $\begin{array}{l}-6.00 \\
-3.86 \\
-4.26 \\
\end{array}$ & $\begin{array}{r}-3.62 \\
-2.59 \\
-2.44 \\
\end{array}$ \\
\hline
\end{tabular}

Vote-Slopes are for least-squares best linear fits: data from durations greater than 300 inse'c are not inchided. 
Table 5

Results of Experiment $\boldsymbol{\Gamma}^{*}$ : Effects of Noise Floor on Detection and Recognition of Increments and Decrements in a Pure Tone

\begin{tabular}{|c|c|c|c|c|c|}
\hline $\begin{array}{l}\bar{\Xi} \\
\bar{E} \\
\vdots \\
\bar{z} \\
z\end{array}$ & $\begin{array}{c}\text { Dura- } \\
\text { tion } \\
(1 \text { sec) }\end{array}$ & $\begin{array}{c}\text { Increment } \\
\text { Detection } \\
\text { (dB) }\end{array}$ & $\begin{array}{l}\text { Decrement } \\
\text { Detection } \\
\text { (dB) }\end{array}$ & $\begin{array}{l}\text { Percent } \\
\text { Correct } \\
\text { in } \\
\text { Detec- } \\
\text { tion* }\end{array}$ & $\begin{array}{c}\text { Percent } \\
\text { Correst } \\
\text { in } \\
\text { Recog- } \\
\text { nition }\end{array}$ \\
\hline & & \multicolumn{4}{|c|}{$O E B$} \\
\hline No & $\begin{array}{r}15 \\
50 \\
100 \\
225 \\
600\end{array}$ & $\begin{array}{r}-9.1 \\
-9.1 \\
-10.4 \\
-12.2 \\
-13.9\end{array}$ & $\begin{array}{r}-8.7 \\
-9.0 \\
-9.3 \\
-11.6 \\
-15.3\end{array}$ & $\begin{array}{l}73.5 \\
83.5 \\
76.0 \\
75.5 \\
77.5\end{array}$ & $\begin{array}{l}60 \\
78 \\
78 \\
90 \\
91\end{array}$ \\
\hline Yes & $\begin{array}{r}15 \\
50 \\
100 \\
225 \\
600 \\
\end{array}$ & $\begin{array}{r}-2.7 \\
-6.8 \\
-7.8 \\
-9.9 \\
-12.2 \\
\end{array}$ & $\begin{array}{r}-3.9 \\
-6.6 \\
-5.8 \\
-8.7 \\
-10.1 \\
\end{array}$ & $\begin{array}{l}75.0 \\
72.5 \\
74.0 \\
69.0 \\
71.5 \\
\end{array}$ & $\begin{array}{l}74 \\
81 \\
77 \\
88 \\
90 \\
\end{array}$ \\
\hline & & \multicolumn{4}{|c|}{$\mathrm{O} R Z$} \\
\hline No & $\begin{array}{r}15 \\
50 \\
100 \\
225 \\
600\end{array}$ & $\begin{array}{r}-7.8 \\
-9.9 \\
-9.5 \\
-10.9 \\
-10.4\end{array}$ & $\begin{array}{l}-7.0 \\
-9.7 \\
-8.4 \\
-9.3 \\
-9.7\end{array}$ & $\begin{array}{l}73.0 \\
71.0 \\
83.0 \\
75.5 \\
70.5\end{array}$ & $\begin{array}{l}72 \\
81 \\
78 \\
86 \\
93\end{array}$ \\
\hline Yes & $\begin{array}{r}15 \\
50 \\
100 \\
225 \\
600 \\
\end{array}$ & $\begin{array}{l}-5.2 \\
-7.3 \\
-9.1 \\
-9.5 \\
-9.5 \\
\end{array}$ & $\begin{array}{l}-5.1 \\
-7.4 \\
-7.9 \\
-8.1 \\
-9.3 \\
\end{array}$ & $\begin{array}{l}71.0 \\
72.0 \\
66.5 \\
72.5 \\
70.0 \\
\end{array}$ & $\begin{array}{l}57 \\
66 \\
67 \\
70 \\
95 \\
\end{array}$ \\
\hline & & \multicolumn{4}{|c|}{ O KR } \\
\hline No & $\begin{array}{r}15 \\
50 \\
100 \\
225 \\
600\end{array}$ & $\begin{array}{r}-7.8 \\
-8.7 \\
-10.4 \\
-10.9 \\
-10.9\end{array}$ & $\begin{array}{r}-7.4 \\
-8.4 \\
-9.3 \\
-9.3 \\
-10.1\end{array}$ & $\begin{array}{l}70.0 \\
77.0 \\
76.5 \\
78.0 \\
76.5\end{array}$ & $\begin{array}{l}55 \\
62 \\
64 \\
77 \\
98\end{array}$ \\
\hline Yes & $\begin{array}{r}15 \\
50 \\
100 \\
225 \\
600\end{array}$ & $\begin{array}{r}-5.2 \\
-7.3 \\
-8.1 \\
-10.4 \\
-9.5\end{array}$ & $\begin{array}{r}-5.3 \\
-7.9 \\
-7.4 \\
-8.4 \\
-10.6\end{array}$ & $\begin{array}{l}74.0 \\
74.5 \\
70.0 \\
70.0 \\
71.5\end{array}$ & $\begin{array}{l}72 \\
73 \\
89 \\
73 \\
98\end{array}$ \\
\hline
\end{tabular}

* Average of increment and decrement detection. rounded off to nearest 0.5 .

detection performance was directly measured after the threshold was estimated.

The durations used were $15,50,100,225$, and $600 \mathrm{msec}$. The total SPL of the noise (which was not filtered) was $50 \mathrm{~dB}$.

\section{Results and Discussion}

Table 5 gives the results of the experiment, both with and without noise background (the nonnoise data are summarized from Macmillan, 1971). The absolute levels of the thresholds are, of course, higher in the presence of noise.

Table 4 presents the slopes of the best-fitting intensity-duration functions. computed using only the shortest four durations. ${ }^{6}$ It can be seen that the average slopes increase (in absolute value) in the presence of noise (for increments from 2.61 to $4.71 \mathrm{~dB}$ per log unit of duration). In fact. a difference in this direction occurs for all Os. for both increments and decrements.

In view of this revival of temporal integration in the presence of noise. the off-frequency listening hypothesis predicts a severe reduction in the detection-recognition disparity. This reduction does not occur. It is possible. of course. that the "off-frequency" energy was not entirely masked by the noise and that some off-frequency listening may still be occurring. What the data clearly show is that off-frequency listening is not the main explanation of the detection-recognition disparity. If it were, substantial changes in the slope of the intensity-duration function would be accompanied by substantial changes in the extent of the detection-recognition disparity.

\section{EXPERIMENT V: \\ UNCERTAIN INCREMENT-DECREMENT DETECTION IN THE PRESENCE OF NOISE}

Macmillan (1971) offered evidence for change detection from a second type of experiment, the uncertain detection paradigm. If the signal presented in one of the two temporal forced-choice intervals may be, on any given trial, either an increment or a decrement. then a signal detection theory analysis which assumes that the sensory events resulting from decrements, no change, and increments in the background lie on a single decision axis predicts a decline in performance due to uncertainty. A change detector. on the other hand. should not show this decline. since it does not identify. the signals in the first place. This leads to the prediction that the decline in performance due to uncertainty should be greatest at the longest signal durations, where the change detector contributes least to detection.

This phenomenon could be accounted for by the off-frequency listening hypothesis by assuming that the $O$ tunes his filter off-frequency for short durations, but on-frequency for long durations. At short durations, there is considerable energy splatter, which is identical for increments and decrements: introducing uncertainty concerning the direction of the change will not change the energy spectrum off-frequency, and thus will not harm performance. At long durations, the $O$ is tuned to the signal frequency, and Macmillan's (1971) signal detection theory analysis predicts a decline in performance when the direction of the change is uncertain.

The present experiment investigates whether duration still influences the relative detectability of certain and uncertain signals when a noise floor is present. Under these conditions, the off-frequency listening hypothesis predicts that the duration of the signal will not affect the relative certain-uncertain detectability. Rather, since the $O$ is tuned to the signal frequency, uncertain detection should be uniformly poorer than certain detection. The change detection hypothesis, on the other hand. predicts that uncertain detection will decline 
Table 6

Results of Experiment V: Percent Correct in Certain and Lncertain Detection of Increments and Decrements in a Pure Tone. With and Without a Noise Floor

\begin{tabular}{|c|c|c|c|c|c|c|c|}
\hline \multirow[b]{2}{*}{$\begin{array}{l}\text { Noist } \\
\text { Floor? }\end{array}$} & \multirow[b]{2}{*}{$\begin{array}{c}\text { Duration } \\
\text { (.Isec) }\end{array}$} & \multicolumn{3}{|c|}{$O L B$} & \multicolumn{3}{|c|}{$O R Z$} \\
\hline & & $\begin{array}{l}\text { Increment } \\
\text { Detection }\end{array}$ & $\begin{array}{l}\text { Decrement } \\
\text { Detection }\end{array}$ & $\begin{array}{l}\text { Lncertian } \\
\text { Increment- } \\
\text { Decrement } \\
\text { Detection }\end{array}$ & $\begin{array}{l}\text { Increment } \\
\text { Detection }\end{array}$ & $\begin{array}{l}\text { Decrement } \\
\text { Detection }\end{array}$ & $\begin{array}{l}\text { Uncertain } \\
\text { Increment- } \\
\text { Decrement } \\
\text { Detection }\end{array}$ \\
\hline No & $\begin{array}{r}15 \\
50 \\
100 \\
225 \\
600\end{array}$ & $\begin{array}{l}74 \\
81 \\
86 \\
77 \\
72\end{array}$ & $\begin{array}{l}74 \\
81 \\
79 \\
84 \\
74\end{array}$ & $\begin{array}{l}66 \\
77 \\
77 \\
69 \\
59\end{array}$ & $\begin{array}{l}79 \\
74 \\
74 \\
78 \\
84\end{array}$ & $\begin{array}{l}71 \\
76 \\
70 \\
71 \\
74\end{array}$ & $\begin{array}{l}70 \\
72 \\
75 \\
70 \\
58\end{array}$ \\
\hline Yes & $\begin{array}{r}15 \\
50 \\
100 \\
225 \\
600\end{array}$ & $\begin{array}{l}73 \\
78 \\
73 \\
69 \\
72\end{array}$ & $\begin{array}{l}71 \\
74 \\
73 \\
71 \\
71\end{array}$ & $\begin{array}{l}67 \\
68 \\
67 \\
64 \\
57\end{array}$ & $\begin{array}{l}77 \\
81 \\
82 \\
82 \\
74\end{array}$ & $\begin{array}{l}75 \\
69 \\
72 \\
70 \\
66 \\
\end{array}$ & $\begin{array}{l}69 \\
75 \\
68 \\
68 \\
55 \\
\end{array}$ \\
\hline
\end{tabular}

with duration, relative to certain detection, whether or not a noise floor is present.

\section{Procedures}

The procedures followed were identical to those described in Experiment 4 of Macmillan (1971), which is the no-noise version of this experiment. The noise background and the signal durations were the same as in Experiment IV of the present report. Two of the three Os from Experiment IV completed the experiment.

\section{Results and Discussion}

The data are given in Table 6 for both the noise and no-noise conditions (the latter summarized from Macmillan, 1971). For both conditions, the decline due to uncertainty is large at the longest duration $(600 \mathrm{msec})$ and small at the shortest four durations. At the short durations, the decline is only 4.8 percentage points for no noise background, 6.1 when noise is present; the difference between these two figures, although in the
Fig. 1. The detection-recognition disparity in Experiments I-IV. The difference between percent correct in increment-decrement recognition and mean percent correct in increment and decrement detection, averaged across $O s$, is plotted against signal duration. "Short" rise times are 0.5 and $1.0 \mathrm{msec}$ :"long" rise times are 5.0 and $10.0 \mathrm{msec}$.

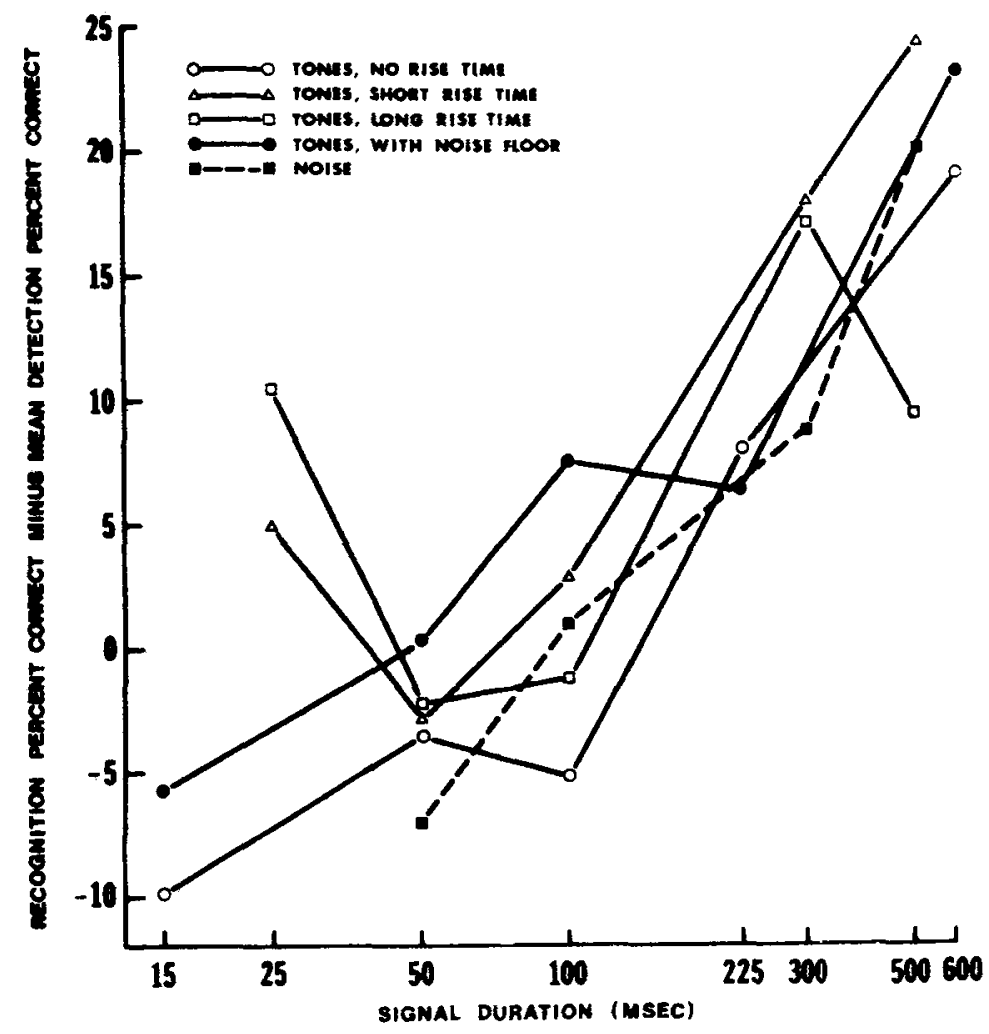




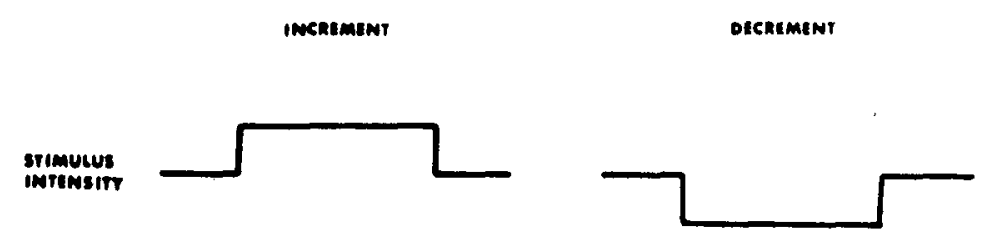

Fig. 2. Hypothesized neural firing rate as a function of time for increments and decrements.

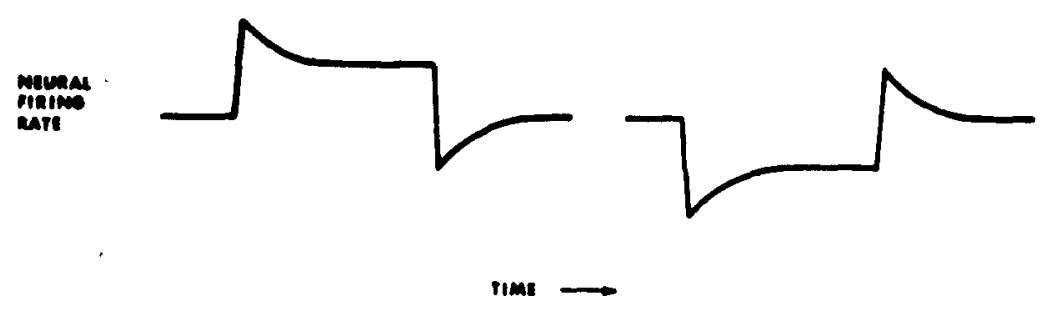

direction predicted by the off-frequency listening hypothesis, is statistically insignificant and is, in fact. entirely due to the data at $100 \mathrm{msec}$. The conclusion is unavoidable that the effect of duration on the decline due to uncertainty, like the detection-recognition disparity, is not influenced by the addition of a noise background and, thus, cannot reasonably be attributed to off-frequency listening.

\section{DISCUSSION}

Figure 1 summarizes the main effect from the first four experiments. It shows the difference between percent correct in detection and recognition, averaged across Os, for all stimulus conditions investigated. (In Experiments I, II, and III, percent correct in detection is assumed to be $73.5 \%$, the theoretical value estimated by the staircase procedure.) One way to estimate the size of the detection-recognition disparity is to find the slopes of the least-squares best-fitting lines to the various sets of points in Fig. 1. These turn out to be: for tones/no rise time, 18.0 percentage points per log unit of duration; for tones/short rise time, 18.2; for tones/long rise time, 6.4 ; for tones in noise background, 16.7 ; for noise, 25.2. Thus, except for the decline of the effect for pure tones with long rise times, there are no compelling differences across conditions. Possibly there is an increased effect with noise, but since this is predicted by no proposed model, the possibility is of little interest.

An acceptable account of these results should deal with at least four surprising aspects of the data: (1) increments are generally easier to detect than are decrements, (2) threshold increment intensity depends more heavily on duration than does threshold decrement intensity, (3) the detection-recognition disparity holds, and (4) uncertain increment-decrement detection depends on duration. A final result, previously reported (Macmillan, 1971), also restricts the possible explanations: (5) detectability of increments in a pure tone is unaffected by randomizing their duration.

The model to be proposed is inspired by Luce and Green's (1972) neural timing theory, in which the decisions made by Os in psychophysical experiments are based on interarrival times (IATs) between successive neural pulses. Changes in stimulus intensity are assumed to lead to changes in the average (Poisson) rate at which the pulses arrive, and thus to changes in the distribution of IATs. This theory is motivated in part by physiological data on IATs; such data provide a convenient starting point for the present analysis.

Physiological data have not been obtained under stimulus conditions identical to those used in the present study. However, a good deal is known about responses to similar signals in the absence of a background (Kiang, 1965: Goldstein, Hall, \& Butterfield, 1968: Moller, 1969). It is consistently found that turning on an auditory signal leads to a large increase in neural firing rate, which then declines as the signal continues. In the auditory nerve, the offset of the signal leads to a brief suppression of firing below the baseline rate (Kiang, 1965); in the cortex, cells have been found which are sensitive to onsets and offsets (Goldstein et al, 1968). A safe conclusion is that an increment in the intensity of an auditory background is not neurally reflected just as a change in firing rate for the duration of the increment. Rather, there are strong transient effects.

The exact nature of the transient information available to the $O$ is, of course, not completely specified by these data, but the following is a simple possibility. Suppose all neural information relevant to the O's task in these experiments is carried on one neural channel, on which pulses are carried at a Poisson rate, the mean of which is determined by the stimulus waveform. Whenever the level of the background increases quickly, there is a sizable jump in the Poisson rate, declining over a short period to a stable rate higher than the initial one. Whenever the level of the background decreases quickly. there is a sizable drop in the firing rate. which then 
increases over a short period to a stable rate lower than the initial one. Figure 2 shows schematically the effects produced by increments and decrements on Poisson rate under this hypothesis.

Now, if the $O$ is using IATs as the basis for his decisions in these experiments, what should he do? Luce and Green (1972, p. 30) argue that neural events are sufficiently rare in detection experiments that few IATs are observed by the listener before a decision is made. It is clear from Fig. 2 that either very short or very long IATs might result from a signal of either type. Suppose the $O$ collects the first $K$ IATs in each interval, where $K$ is fixed by the O's "memory capacity," and uses decision rules of the following type: In forced-choice detection, respond to the interval in which more long and short (rather than moderate) IATs are observed; in recognition, locate the increment in the interval with the higher ratio of short to long IATs. The criteria by which the $O$ decides whether an IAT is fast, moderate, or slow may be reasonably supposed to be insensitive to duration; the value of $\mathrm{K}$, the memory capacity (Luce \& Green, 1972), also does not depend on duration. Thus, the O's strategy is consistent with the data from the randomized duration experiment (Macmillan, 1971, Experiment 5).

When the signal duration is short, larger proportions of the $\mathrm{K}$ intervals collected by the $\mathrm{O}$ will be both long and short if either an increment or a decrement is presented. This will lead to good detection performance but poor recognition performance. At longer durations, most of the observed IATs will come from the part of the signal interval in which the Poisson rate is stable, and good recognition as well as good detection will be possible. Thus, the detection-recognition disparity will occur. A similar argument accounts for the uncertain detection effect (Experiment 5).

If $\mathrm{K}$ is not too large and the signal duration is long, then an increment is more likely than is a decrement to fill the store before the observation interval ends; thus, increments will be more detectable than decrements. At short durations, where a stable firing rate is attained only briefly, this is not true, and increments and decrements will be approximately equally detectable: thus, the slope of the intensity-duration relation will be steeper for increments than for decrements. Thus, we see that a model of this sort can qualitatively account for all the phenomena listed above: I do not attempt here to determine values for the many parameters and fit the resulting model quantitatively. The main point of this discussion is to indicate a direction one might take in devising models which satisfy the restrictions imposed by the data.

\section{Temporal Integration}

Macmillan (1971) argued that any two-process model which could account for the detection-recognition disparity must also predict a shallow intensity-duration relation. Yet, in the present study, the disparity was shown to be largely independent of the intensity-duration relation (see Table 7 and Fig. 1). The apparent contradiction arises from the ambiguity of the prediction: compared to what should the slope be shallow? The fact that the different stimulus situations used in this study yield different intensity-duration relations is not crucial, since the nature of this relation depends on many factors (among them, the usefulness of off-frequency listening).

What is true is that a model including two processes-change detection and integrative detection-predicts less temporal integration than-does an otherwise identical model which is purely integrative. Thus, we could test the change detection hypothesis by looking for intensity-duration relations which are more shallow than those predicted by integrative models. For tonal stimuli, the predictions of existing models depend on a large number of assumptions concerning internal processing of the stimulus; there is no agreement on one predicted slope. The simple energy detector for noise signals (Green \& Swets, 1966) predicts a slope of $5.0 \mathrm{~dB}$ per $\log$ unit, which is in fact slightly greater than the 4.1 and 3.5 found in Experiment III for increments and decrements, although less than some other estimates (e.g., Rochester, 1971). Of course, the estimated slope depends on the range of durations used, since the extent of integration apparently declines with increasing duration. The fact that the durations used in the present study were relatively long may help to account for the rather shallow intensity-duration relations observed.

\section{CONCLUSIONS}

The experiments reported here place a number of restrictions on models of auditory detection. Clearly, Os process the stimulus waveform in the time domain, and the information they extract from it is more complex

Table 7

Average Slopes of Intensity-Duration Relations

\begin{tabular}{|c|c|c|c|c|c|c|}
\hline Stimulus Condition & $\begin{array}{l}\text { Experi- } \\
\text { ment }\end{array}$ & $\begin{array}{c}\text { Number } \\
\text { of } \\
\text { Os }\end{array}$ & $\begin{array}{l}\text { Number } \\
\text { of Con- } \\
\text { ditions }\end{array}$ & $\begin{array}{c}\text { Durations } \\
\text { (Alsec) }\end{array}$ & $\begin{array}{c}\text { Increment } \\
\text { Slope } \\
\text { (dB/Log } \\
\text { Lnit) }\end{array}$ & $\begin{array}{c}\text { Decrement } \\
\text { Slope } \\
\text { (dB Log } \\
\text { Lnit) }\end{array}$ \\
\hline Tone. no rise time & 4 & 3 & 3 & $15-225$ & -2.61 & -1.88 \\
\hline Tone. short $(0.5-$ or $1.0-\mathrm{msec})$ rise time & 1.2 & 4 & 8 & $25-300$ & -3.26 & -2.63 \\
\hline Tone. long $(5.0$. or $10.0-\mathrm{msec})$ rise time & 1.2 & 4 & 6 & $25 \cdot 300$ & -4.32 & -2.71 \\
\hline Tone with noise flow & 4 & 3 & 3 & $15-225$ & -4.71 & 2.88 \\
\hline Noise & 3 & 2 & 4 & $50-300$ & -4.07 & $-\$ .51$ \\
\hline
\end{tabular}


than is supposed by straightforward integrative models. The common assumption that the $O$ reduces the information in a single observation interval to a single number je.g. an energy estimate or a correlation coefficient) is too simple. On the other hand, the data do not merely show. as usual. that perception is more complicated than heretofore thought: they also indicate that many of the subtle abilities often attributed to Os (listening only for a period of time equal to the signal duration or setting a filter in optimal locations) should not. and need not, be assumed.

\section{REFERENCES}

Creelman, C. D. Loudness and detectability scaling of bandpass-filtered short tones. Journal of the Acoustical Society of America. 1964, 36, 966-967.

Garner. W. R. The effect of frequency spectrum on temporal integration of energy in the ear. Journal of the Acoustical Society of America, 1947, 19, 808-815.

Goldstein, M. H., Hall, J. L., II. \& Butterfield, B. O. Single-unit activity in the primary auditory cortex of unanesthetized cats. Journal of the Acoustical Society of America. 1968. 43. 444-455.

Green, D. M., \& Swets, J. A. Signal detection theory and psychophysics. New York: Wiley, 1966.

Hamilton, P. M. Noise masked thresholds as a function of tonal duration and masking noise band width. Journal of the Acoustical Society of America. 1957, 29, 506-511.

Kiang, N. Y.S. Discharge patterns of single fibers in the cat's auditory nerve. Research Monograph No. 35. Cambridge, Mass: M.I.T. Press, 1965.

Larkin, W. D., \& Norman. D. A. An extension and experimental analysis of the neural quantum theory. In R. C. Atkinson (Ed.), Studies in mathematical psy'chology. Palo Alto: Stanford University Press, 1964.

Leshowitz, B., \& Wightman, F. L. On-frequency masking with continuous sinusoids. Journal of the Acoustical Society of America, 1971, 49, 1180-1190.

Leshowitz, B., \& Wightman, F. L. On the importance of considering the signal's frequency spectrum: Some comments on Macmillan's "Detection and recognition of increments and decrements in auditory intensity" experiment. Perception \& Psychophysics, 1972, 12, 209-210.

Lindner, W. A. Recognition performance as a function of detection criterion in a simultaneous detection-recognition task. Journal of the Acoustical Society of America, 1968, 44, 204-211.

Luce, R. D. Detection and recognition. In R. D. Luce. R. R. Bush, and E. Galanter (Eds.), Handbook of mathematical psychology. Vol. 1. New York: Wiley, 1963.

Luce, R. D., \& Green, D. M. A neural timing theory for response times and the psychophysics of intensity. Psychological Review, 1972, 79, 14-57.

Macmillan, N. A. Detection and recognition of increments and decrements in auditory intensity. Perception \& Psychophysics, $1971,10,233-238$.

Macmillan, N. A. Change detection and off-frequency listening: A reply to Leshowitz and Wightman. Perception \& Psychophysics, 1972, 12, 211-212.

Moller, A. R. Unit responses in the rat cochlear nucleus to repetitive, transient sounds. Acta Physiologica Scandinavica, $1969,75,542-551$.

Penner, M. J. The effect of payoffs and cue tones on detection of sinusoids of uncertain frequency. Perception \& Psychophysics. 1972.11.198-202.

Rochester. S. Detection and duration discrimination of noise increments. Journal of the Acoustical Society of America. 1971. $+9.1783-1789$.

Scharf. B. Critical bands. In J. V. Tobias (Ed.). Foundations of modem auditory theory. Vol. 1. New York: Academic Press. 1970.

Shipley. E. F. Detection and recognition: Experiments and choice models. Journal of Mathematical Psychology. 1965. 2. 277-311.

Stevens. S. S., Morgan, C. T., \& Volkmann, J. Theory of the neural quantum in the discrimination of loudness and pitch. American Journal of Psychology. 1941, 54, 315-335.

Tanner. W. P. Theory of recognition. Journal of the Acoustical Society of America. 1956, 28. 882-888.

Wightman. F. L. Detection of binaural tones as a function of masker bandwidth. Journal of the Acoustical Society of America. 1971, 50, 623-636.

\section{NOTES}

1. To find the power spectrum, we first compute the amplitude spectrum of the envelope, then multiply by the amplitude spectrum of the sine wave to give the amplitude spectrum of the tone burst (this is sketched in Wightman. 1971). For a signal whose envelope increases linearly for $\mathrm{r}$ sec. has a constant (unit) value for $T$ sec, and decreases linearly to zero in I sec, this yields:

$$
\begin{aligned}
F(\omega)= & \left(\frac{T+r}{2}\right)\left[\frac{\sin 1 / 2\left(\omega-\omega_{0}\right)(T+r)}{1 / 2\left(\omega-\omega_{0}\right)(T+r)} \cdot \frac{\sin ^{1} 2\left(\omega-\omega_{0}\right) r}{{ }^{1}=\left(\omega-\omega_{0}\right) r}\right. \\
& \left.+\frac{\sin 1 / 2\left(\omega+\omega_{0}\right)(T+r)}{1 / 2\left(\omega+\omega_{0}\right)(T+r)} \cdot \frac{\sin 1 / 2\left(\omega+\omega_{0}\right) r}{1 / 2\left(\omega+\omega_{0}\right) \mathbf{r}}\right]
\end{aligned}
$$

The energy spectrum. $|F(\omega)|^{2}$, can now be found in a straightforward. if laborious. manner.

2. The calculations are based on the assumption that, in listening of $f$-frequency, (1) the $O$ is sensitive to those frequencies outside the "critical bandwidth" centered at the signal frequency. and (2) the bandwidth of the internal filter is uninfluenced by duration. The first assumption is too simple-the effective bandwidth of the internal filter clearly depends on task requirements (Penner, 1972). The second assumption is false-critical bandwidth apparently increases as duration decreases (Hamilton, 1957). However, only the reasonable assumption that the region of the spectrum which is off-frequency does not change with signal rise time is critical to the (qualitative) conclusion.

3. This procedure was adopted because the psychometric function for signals which are increments in a pure tone is sometimes found to be linear in $\Delta v / v$ (Stevens, Morgan. \& Volkmann, 1941 ; Larkin \& Norman, 1964).

4. Theoretically, this is an estimate of the point on the psychometric function at which the $O$ is making about $73.5^{\circ}$ r correct decisions. No direct check of this prediction was made; however, in similar experiments, it has been found that $O s$ in fixed-signal-level experiments perform at a slightly ( 5 , or less) poorer level than that calculated theoretically.

5. About half of the conditions in Experiment I were run twice, because the first set of data indicated that the $O$ was not performing as well as he had during practice sessions. In these cases, only the second result is reported, and it is marked as a "replication"; replications tended to be necessary in those conditions with short signal durations. The percent correct in recognition was higher in the replication data than in the original (9 of 11 cases): the detection thresholds were lower ( 21 of 22 cases). Although performing replications in this manner is perhaps not the most elegant of procedures, it does not bias the results in favor of the present arguments. In fact. the procedure was used to insure that the detection-recognition disparity was 
not an artifact of variability in estimated threshold. In Experiments Il and IIl, a smaller number of replications were run. In Lxperiment II, thresholds were higher in 7 of 12 ases: in Experiment III. thresholds were higher in 2 of 2 cases. Percent correct was higher in all cases.)

6. The slopes for the no-noise condition differ from those given for the same data in Macmillan (1971). where an approximation was used [sec lote 2 of Macmillan (1971)], and where all durations were included in the computation.

(Received for publication A pril 19. 1972; revision received August 8, 1972.) 